\title{
THE CHLOROPLAST GLUTAMATE tRNA GENE REQUIRED FOR $\delta$-AMINOLEVULINATE SYNTHESIS
}

by

\author{
SANDY BERRY-LOWE
}

Department of Physiology, Carlsberg Laboratory, Gamle Carlsberg Vej 10, DK-2500 Copenhagen Valby

\begin{abstract}
Keywords: Barley, chloroplast genes $\operatorname{trnE}$ (UUC), $\operatorname{trnY}($ GUA), $\operatorname{trn} D(G U C)$, chlorophyll synthesis
\end{abstract}

The first major intermediate in the tetrapyrrole biosynthetic pathway is $\delta$-aminolevulinate ( $\delta$-ALA). The synthesis of $\delta$-ALA in greening barley requires an RNA ( $\delta$-ALA-RNA) which is aminoacylated with glutamate by a tRNA ligase. $\delta$-ALA-RNA isolated from barley plastids and a synthetic nucleotide oligomer were used as hybridization probes to isolate the gene encoding $\delta$-ALA-RNA from a collection of barley DNA chloroplast clones. Sequence of the barley $\delta$-ALA-RNA reveals a typical tRNA sequence which is identical to the wheat glutamate tRNA gene. The tyrosine and aspartate tRNA genes are closely linked to $\delta$-ALA-RNA on a $1.6 \mathrm{~kb}$ HindIII-EcoRI restriction fragment. The glutamate $T$ RNA gene is transcribed in the dark and in the light under all the conditions tested. SI mapping was used to locate the potential regulatory sequences and to establish that the three tRNAs are processed from a single precursor RNA. A single gene encodes the $\delta$-ALA-RNA which functions in $\delta$-ALA synthesis and the glutamate tRNA which functions in chloroplast protein synthesis. The two RNA products may differ in posttranscriptional modifications.

\section{INTRODUCTION}

Chlorophyll is the major tetrapyrrole in plants and $\delta$-aminolevulinate ( $\delta$-ALA) is the first committed intermediate in this pathway. The synthesis of $\delta$-ALA has been examined in barley and requires a chloroplast glutamyl-tRNA ( $\delta$-ALARNA) (17). $\delta$-ALA-RNA has been isolated from greening barley and sequenced (33). This revealed an anticodon for glutamate and a characteristic glutamate $t R N A$ sequence. It was therefore of interest to determine whether the $\delta$-ALARNA and the glutamate tRNA for protein synthesis are encoded by a single gene and whether the two RNA molecules are differentially ex- pressed at the transcriptional or posttranscriptional level.

Chloroplast glutamate tRNA genes have been sequenced in wheat (31), spinach (14), pea (32, 35 ), tobacco (26), broad bean (21), Euglena (13), and liverwort (27). In all cases, including tobacco (36) and liverwort (27) in which the entire chloroplast genomes have been sequenced, only one glutamate $\mathrm{RNA}$ gene has been identified in the chloroplast DNA. The glutamate tRNA gene is located adjacent to the tyrosine tRNA gene and near to the aspartate $T$ RNA gene. Transcription has been established for pea, tobacco and spinach $(14,26,32)$ and the 5 ' and 3 ' ends of the

Abbreviations: $\delta$-ALA-RNA $=$ RNA involved in $\delta$-aminolevulinate biosynthesis; MOPS $=3$-(N-Morpholino)propanesulfonic acid; ORF $=$ open reading frame; $\mathrm{SDS}=$ sodium dodecyl sulfate; $1 \mathrm{X}$ SSC $=0.15 \mathrm{M}$-sodium chloride $+0.015 \mathrm{M}$-sodium citrate. 
gene have been determined by $\mathrm{S} 1$ mapping in tobacco.

To isolate the barley gene encoding $\delta$-ALARNA and to determine whether it is homologous to the chloroplast glutamate tRNA genes of other species, $\delta$-ALA-RNA and a synthetic nucleotide oligomer identical to part of its sequence were used as hybridization probes. The DNA sequence encoding the $\delta$-ALA-RNA is presented. A single chloroplast gene encodes both the $\delta$-ALA-RNA and the glutamate tRNA. The barley and wheat sequences are nearly identical in the $1.4 \mathrm{~kb}$ region sequenced in both species $(30,31)$. However, the region of homology with tobacco is limited to the TRNA genes and the 60 base pairs nearest the glutamate tRNA gene. The 5' and '3' ends of the transcripts as identified by $\mathrm{SI}$ analysis were determined.

\section{MATERIALS AND METHODS}

\subsection{Plant material}

Hordeum vulgare L. cv. Svalöfs Bonus was grown for seven days at $23^{\circ} \mathrm{C}$. Seedlings routinely received $0,6,12$ or 24 hours of light before harvest. Leaves were harvested, stored on ice and ground in a blender modified with additional razor blades (16).

\subsection{Hybridization probes}

$\delta$-ALA-RNA was isolated from barley plastids as described previously (17). It was either 5 , end-labelled with $\left(\alpha-{ }^{32} \mathrm{P}\right)$ ATP $(>7000 \mathrm{Ci} / \mathrm{mmol})$ by T4 polynucleotide kinase or 3' end-labelled with $\left(5^{\prime}-{ }^{32} \mathrm{P}\right) \mathrm{pCp}(2000-4000 \mathrm{Ci} / \mathrm{mmol})$ by RNA ligase (Pharmacia). Two oligomers were synthesized on an Applied Biosystems Oligonucleotide Synthesizer. Both oligomers correspond to the same region from their respective tRNAs. One corresponds to 18 nucleotides of the $\delta$-ALARNA which has been isolated from barley plastids and sequenced (33). The sequence, 5' GGACATCTCTCTTTCAAG 3' (Figure 5A), is denoted $\delta$-ALA-oligo in the text and is identical to both part of the $\delta$-ALA-RNA (33) and to the wheat chloroplast glutamate tRNA sequence (31). It corresponds to a section of the tRNA from the 3' portion of the D-loop stem to the first base of the 3' portion of the aminoacyl stem and therefore contains the anticodon. The second oligomer corresponds to 18 nucleotides of the glycine tRNA gene (GCC) encoded by the chloroplast and contained on the barley chloroplast clone pHvC35 $(28,29)$. This sequence, 5 ' AAACATCTCCTTGCCAAG 3 ' is denoted GLY-oligo in the text. The synthetic probes were labelled at the 5 ' end with $\mathrm{T} 4$ polynucleotide kinase (22). The barley glutamate tRNA gene, contained on a 224 base pair Sau3A-Asp700 fragment (bases 307-531, Figure 5A) was cloned into the Smal site of the expression vector pGEM3 (24) (Promega Biotec). This clone is pGHCglu3. An RNA probe was made by transcription of the linearized plasmid according to the manufacturers instructions by incorporating $\left(\alpha-{ }^{32} \mathrm{P}\right)$ UTP or CTP $(>600 \mathrm{Ci} / \mathrm{mmol})$ into the reaction mix. All isotopes were purchased from New England Nuclear.

\subsection{Isolation of the $\delta$-ALA-RNA gene}

High molecular weight barley DNA was isolated according to NAGAO et al. (25) except that $0.1 \%$ Triton was used and the Percoll gradients were omitted. Chloroplast DNA was isolated as described by KOLODNER and TEWARI (19) except that after lysis of chloroplasts and phenol extraction, DNA was purified by cesium chloride density gradient centrifugation (11). Barley endosperm DNA was a gift from A. BRANDT.

Plasmid DNA minipreparations were made by the alkali method (2). Plasmid DNA was also purified from one liter amplified cultures with cesium chloride gradient centrifugation $(5,12)$.

Subcloning into $\mathrm{pUCl} 3, \mathrm{pUCl} 8$ (38), or pGEM3 plasmids, fine structure restriction mapping, and insert preparation from agarose and acrylamide gels was as described (34). Colony hybridization was according to (9). The nucleotide sequence was determined after endlabelling, restriction digestion and purification of fragments according to MAXAM and GILBERT (23).

Hybridizations using $\delta$-ALA-RNA or the synthetic oligomers as probes were carried out in $6 \mathrm{X}$ SSC, $0.25 \%$ blotto ( 15 ), $0.1 \%$ SDS at 56 or $42^{\circ} \mathrm{C}$, respectively. Filters were washed with $6 \mathrm{X} \mathrm{SSC}$ at $52{ }^{\circ} \mathrm{C}$. Hybridizations with the $\delta$-ALA-oligo could be washed even at $60{ }^{\circ} \mathrm{C}\left(\mathrm{Td}=52{ }^{\circ} \mathrm{C}\right)$ without much loss of the signal. 


\subsection{Analysis of RNA}

Chloroplasts were isolated according to GruisSEM et al. (8) except the Percoll gradients were $34 \%$ Percoll (1) containing 1\% Ficoll, $1 \%$ bovine serum albumin, and $3 \%$ polyethylene glycol in grinding medium. The resuspended chloroplast pellet was layered onto this mix in Beckman screw cap 60Ti tubes and centrifuged for 20 minutes at $40,000 \times \mathrm{g}$. Chloroplasts were collected, lysed, and the RNA purified by centrifugation through cesium chloride cushions for 12 hours at $125,000 \times \mathrm{g}$ (29). Soluble RNAs were isolated directly from leaf tissue by grinding in guanidinium hydrochloride (4) and precipitation after cresol treatment (18).

RNAs were denatured, electrophoresed through 1\% MOPS-agarose gels, and blotted onto nitrocellulose as described by MANIATIS et al. (22). Hybridizations of Northern blots used RNA from SP6 transcription of pGHCglu 3 as the probe. Hybridization was carried out according to the manufacturers instructions at $56{ }^{\circ} \mathrm{C}$. Filters were washed in $2 \mathrm{X} \mathrm{SSC}$ at $56^{\circ} \mathrm{C}$ and exposed to film (XAR, Kodak) for at least four hours.

SI nuclease analysis was carried out as described by FAVALORO et al. (7) to establish the 5' and 3' ends of the RNA transcripts. Five micrograms of RNA isolated from plants grown under several light regimes were used. The labelled DNA fragments were isolated for S1 hybridization as described for sequence analysis. Several DNA fragments were used in order to establish the ends for each IRNA gene transcript and are described in the text. Hybridizations between RNAs and DNA templates were carried out in $10 \mu \mathrm{l}$ in capillary tubes at $48^{\circ} \mathrm{C}$ overnight. The $\mathrm{S} 1$ digestion was performed with 1000 units of S1 nuclease (Sigma) per reaction. S1 resistant hybrids were visualized by autoradiography after electrophoresis on 6 or $8 \%$ acrylamide-urea gels.

\section{RESULTS}

\subsection{Isolation of the $\delta$-ALA-RNA gene}

Four bands of hybridization were detected when end-labelled $\delta$-ALA-RNA was hybridized to chloroplast DNA digested with HindIII (Figure 1). No hybridization was detected to the total

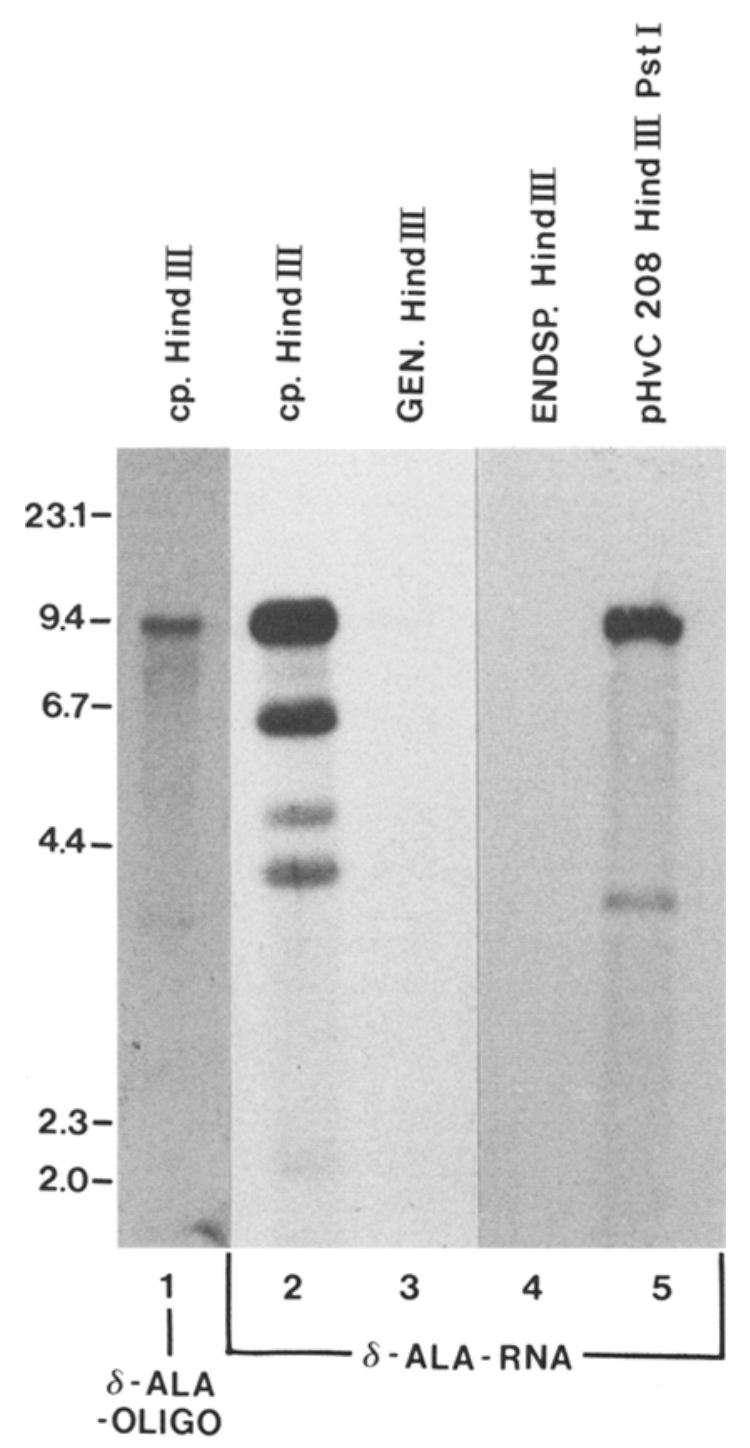

Figure l. Autoradiogram of hybridization of $\delta$-ALARNA and $\delta$-ALA-oligo to the barley chloroplast genome. Five micrograms of chloroplast (lanes 1 and 2), total genomic (lane 3), or endosperm (lane 4) DNA were digested with HindIII. Lane 5 contains one microgram of the barley chloroplast clone $\mathrm{pHvC208}$ digested with HindIII and Pstl. All were electrophoresed on a $1 \%$ agarose gel, transferred to nitrocellulose and hybridized with $\delta$-ALA-oligo (lane 1) or $\delta$-ALA-RNA (lanes 2-5). Lambda DNA digested with HindIII was used as size markers and these are shown in kbp on the left. 
A

B
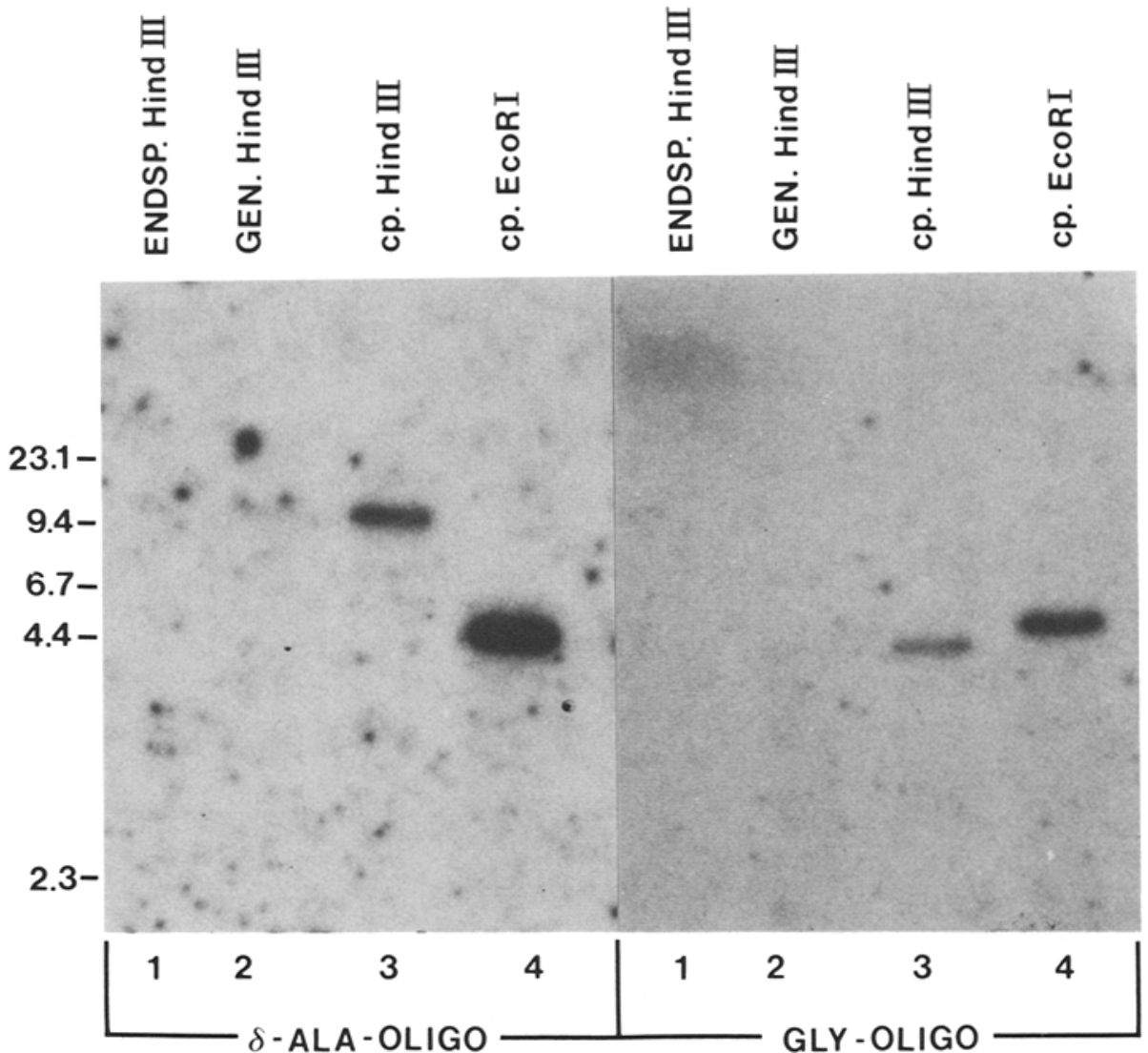

Figure 2. Autoradiogram of synthetic oligomers hybridized to the barley chloroplast genome. Five micrograms of endosperm (lane 1), total genomic (lane 2), or chloroplast (lanes 3 and 4) DNA was digested with HindIII or EcoRI, electrophoresed on a $1 \%$ agarose gel and transferred to nitrocellulose. Filter A was hybridized with the $\delta$-ALA-oligo synthetic probe and filter B with the GLY-oligo synthetic probe. Standard sizes are shown in kbp on the left.

genomic or endosperm DNAs, confirming that the $\delta$-ALA-RNA is chloroplast encoded. The barley chloroplast genome was subcloned into the plasmids $\mathrm{pBR} 322$ and $\mathrm{pBR} 325$ by POULSEN (29). These clones were hybridized to $\delta$-ALARNA. Of particular interest were the clones pHvC35 and pHvC208 which contain a common $3.9 \mathrm{kbp}$ PstI-HindIII fragment (Figure 4). Hybridization of end-labelled $\delta$-ALA-RNA to dot blots of these clones has been shown previously (17). Digestion of the clone pHvC208 (29) with HindIII and Pstl for Southern blot analysis released five fragments including a $9.5 \mathrm{kbp}$ fragment and the $3.9 \mathrm{kbp}$ fragment. Hybridiza- tion occurred primarily to the $9.5 \mathrm{kbp}$ fragment of the $\mathrm{pHvC2} 28$ clone rather than to the common $3.9 \mathrm{kbp}$ fragment (Figure 1). The synthetic oligomer $\delta$-ALA-oligo hybridized only to the 9.5 kbp HindIII fragment of the chloroplast DNA. These results were further confirmed by hybridization of the synthetic $\delta$-ALA-oligo and GLY-oligo probes to nuclear and chloroplast DNAs. The glycine tRNA oligomer was used because it is encoded on pHvC35 (28). Hybridization with these synthetic probes distinguished between the $\mathrm{pHvC} 35$ and $\mathrm{pHvC} 208$ fragments (Figure 2). Both oligomers hybridized to the same EcoRI fragment of approximately 
A

B

C

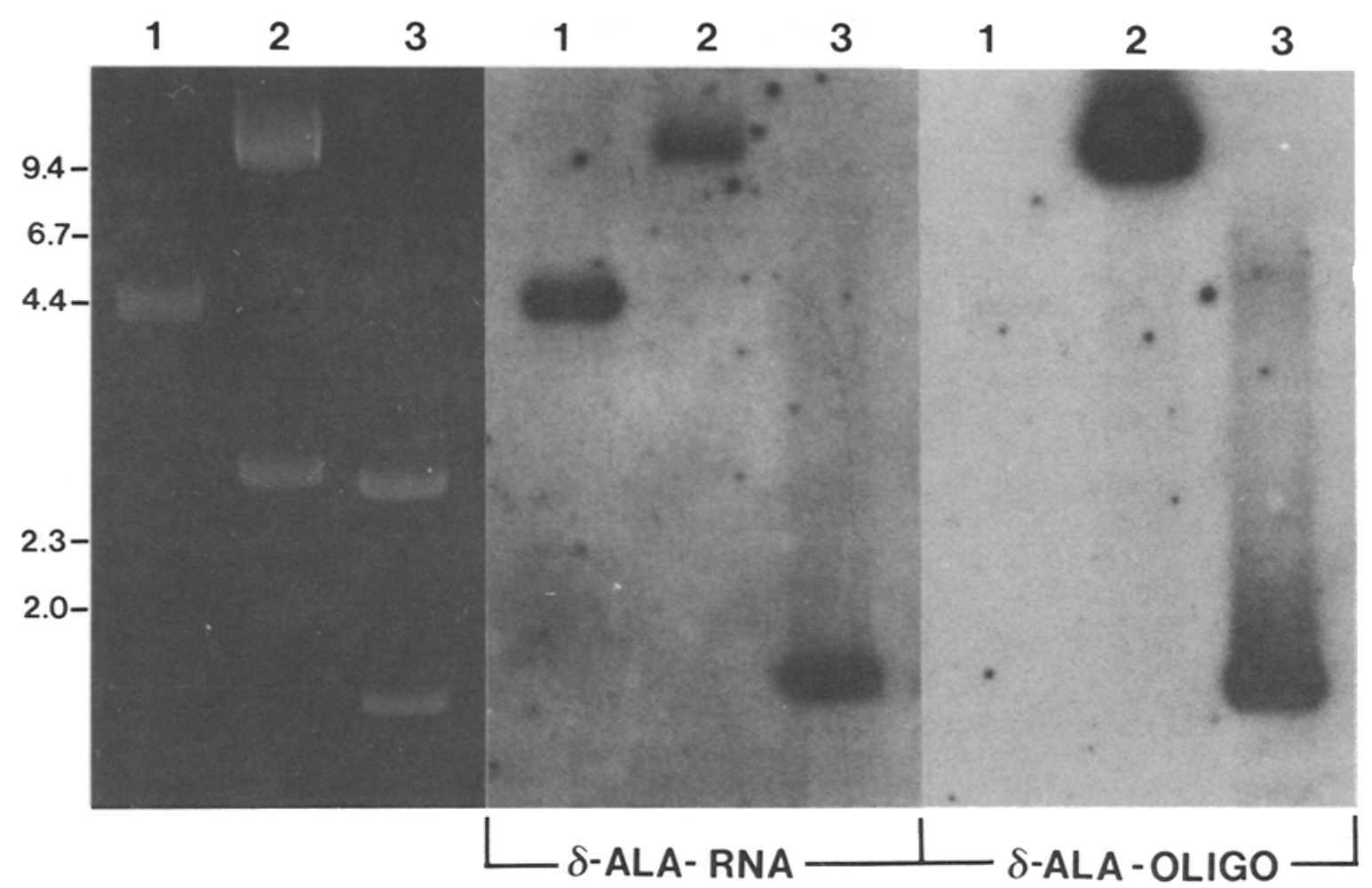

Figure 3. Hybridization of $\delta$-ALA to barley chloroplast subclones. One microgram of the barley chloroplast clone $\mathrm{pHvC35}$ (lane 1), or subclones of pHvC208, pHvC208-9.5 (lane 2) and pHvC208-1.6 (lane 3) were digested with HindIII, HindIII, or HindIII and EcoRI, respectively, to release the cloned insert and were electrophoresed on $1 \%$ agarose gels. The insert of $\mathrm{pHvC} 35$ is the same size as the plasmid vector. They were transferred to nitrocellulose and autoradiographed after hybridization with $\delta$-ALA-RNA (B) or $\delta$-ALA-oligo (C). The ethidium bromide stained gel is shown in panel A. Standard sizes are shown in kbp on the left.

$4.6 \mathrm{kbp}$. However, each hybridized only to their respective HindIII clones (GLY-oligo to the 4.3 $\mathrm{kbp}$ of pHvC35 and $\delta$-ALA-oligo to the $9.5 \mathrm{kbp}$

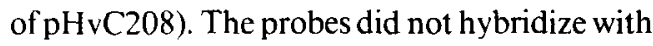
nuclear DNA.

The $9.5 \mathrm{kbp} \mathrm{HindIII} \mathrm{fragment} \mathrm{from} \mathrm{pHvC} 208$ was subcloned into $\mathrm{pUC13}$ to generate pHvC208-9.5. Preliminary restriction site mapping demonstrated that the restriction endonucleases Apal, EcoRI, Hpall, and SphI cleaved the fragment once (data not shown). A $1.6 \mathrm{kbp}$ HindIII-EcoRI fragment (Figure 4) which hybridized to the $\delta$-ALA probes was subcloned into $\mathrm{pUCl} 8$ to generate $\mathrm{pHvC208-1.6}$. The $\delta$ ALA-RNA hybridized to the subcloned 9.5 and
$1.6 \mathrm{kbp}$ inserts of $\mathrm{pHvC} 208$ and also to the pHvC35 insert (Figure 3). The $\delta$-ALA-oligo probe hybridized only to the $\mathrm{pHvC} 208$ inserts.

\subsection{Characterization of the gene}

The fine structure restriction enzyme mapping and sequencing strategy of the $1.6 \mathrm{kbp}$ HindIII-EcoRI insert is presented in Figure 4. The Haelll, Hinfl, and Rsal fragments were subcloned into the Smal site of pUCl8 for sequencing. To confirm the sequence across the HindIII site, an Ncol-Pvul fragment spanning the site (Ncol at base 4140 in $\mathrm{pHvC} 35$ (28) to 


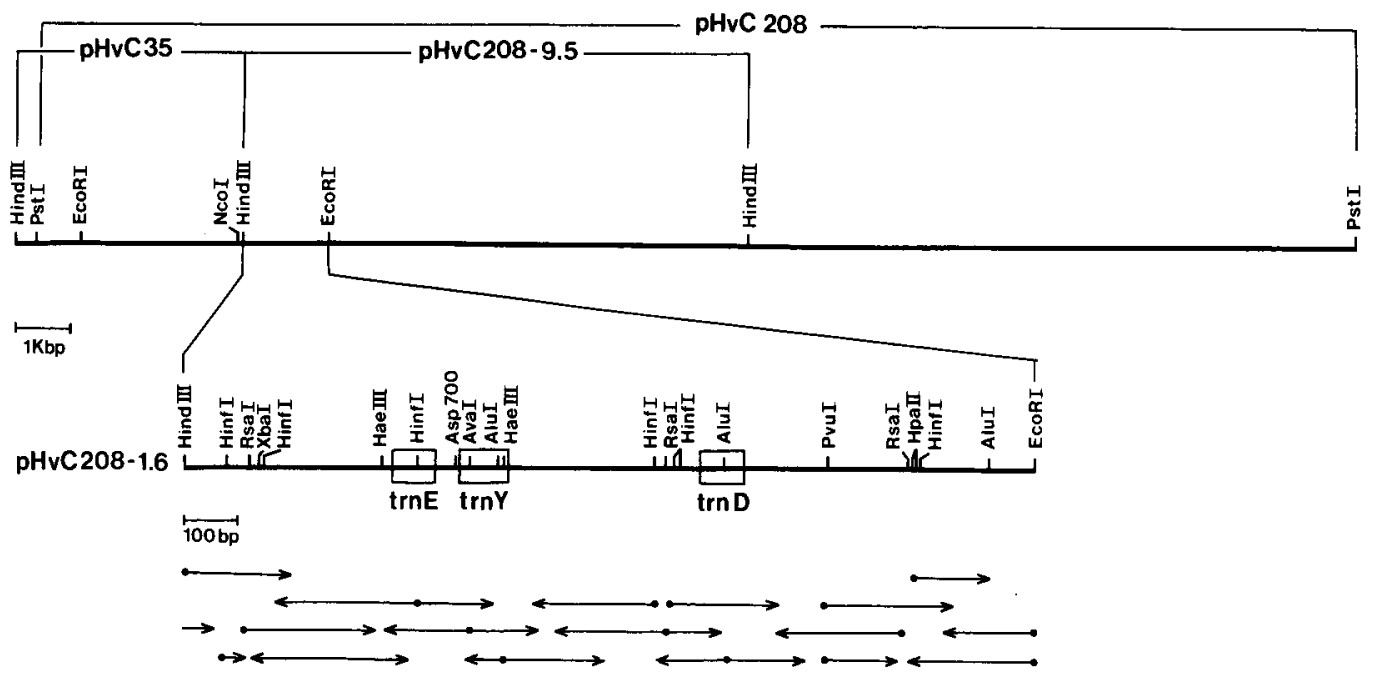

Figure 4. Physical map and sequencing strategy of the $1.6 \mathrm{kbp}$ HindIII-EcoRI subclone. The subcloned fragment is shown relative to the barley chloroplast genome. The arrows indicate the origin and extent of DNA sequences. Only relevant restriction sites are shown. The locations of the tRNA genes for glutamate (trnE), tyrosine (trnY), and aspartate $(\operatorname{trnD})$ are shown as boxes.

Pvul at base 1224 in $\mathrm{pHvC208-1.6)} \mathrm{was} \mathrm{isolated}$ from the $\mathrm{pHvC208}$ insert and sequenced.

Comparison of this sequence with tRNA sequences reveals that the $1.6 \mathrm{kpb}$ fragment encodes three tRNA genes, glutamate (trnE, UUC), tyrosine (trnY, GUA) and aspartate (trnD, GUC) tRNA (Figure 5A). The cloverleaf structures of the three $t R N A s$ are shown (Figure $5 B)$. The trnE is 73 nucleotides long, $\operatorname{trn} \mathrm{Y}$ is 82 and $\operatorname{trnD}$ is 75 . In all chloroplast glutamate tRNA genes there is an A at nucleotide 53 which can pair with a $U$ at nucleotide 61 rather than the "invariant" G-C pair found in other chloroplast tRNA genes (Figure 5B) $(14,26,30,31,35)$. The sequenced $\delta$-ALA-RNA gene from barley was therefore identified as the glutamate tRNA gene.

These three barley chloroplast tRNA genes show strong homology with their counterparts in other chloroplast genomes. The barley chloroplast trnE gene was identical to the wheat chloroplast gene and more than 95\% homologous to the tobacco, pea and bean chloroplast genes. The trnY gene was identical to that of wheat and $96 \%$ homologous to the dicot sequences. The barley trnD gene was identical to that of wheat and differed in only one nucleotide from that of tobacco.
The nucleotide sequences of the regions flanking the three encoded tRNAs in barley and wheat were compared (Figure 5A). Approximately 400 bases in barley and 250 bases in wheat 5' of the trnE gene were compared. In barley there is an insertion of 153 bases in the region close to the HindIII site. There is an inverted repeat five nucleotides in length on either side of the insertion. In the remaining 5 , region there were only six base changes and three small insertions. The barley sequence was also compared with those of the dicots, but the homology disappeared within approximately 60 nucleotides upstream of trnE. In the 3' flanking region there were only four nucleotide changes and seven small insertions or deletions between barley and wheat while there was no homology with the tobacco sequence.

The regions between the three encoded tRNAs also show homology with the homologous regions in other plant species. The barley and wheat sequences are identical in the trnE-trnY intergenic region. There was approximately $77 \%$ overall sequence homology between this region in barley (61 bp) and tobacco (59 bp). There were nine nucleotide changes plus four insertions or deletions (less than $15 \mathrm{bp}$ ) in the 
trnY-trnD intergenic region when barley was compared with wheat. When this region of barley was compared with tobacco there was no apparent homology although this was difficult to determine since it is $69 \% \mathrm{~A}$ and $\mathrm{T}$ and approximately 100 nucleotides in length in tobacco and 350 in barley and wheat.

\subsection{Analysis of RNA}

Steady state levels of the three RNAs were examined by hybridizing the pGHCglu 3 transcript to RNAs which had been diluted sequentially and spotted onto nitrocellulose. These RNAs were isolated from barley plants receiving $0,6,12$, or 24 hours of light before harvest. The steady state levels of RNA did not change during the first 24 hours of greening. Transcription was easily detectable after 16 hours exposure when $100 \mathrm{ng}$ of any of the RNAs were spotted (data not shown). The pattern of hybridization was also the same when these RNAs were electrophoresed, blotted onto nitrocellulose, and hybridized. An example of an autoradiogram showing the sizes of steady state transcripts detected with RNA isolated after six hours illumination is shown in Figure 6. One large presumptive precursor of approximately 2000 nucleotides was detected as well as RNAs of approximately 450 and 230 nucleotides. Transcripts of the processed size ( 75 nucleotides for $\operatorname{trnE}$ ) were also observed.

The large size of the presumptive precursor suggests that all three tRNA genes are cotranscribed, as has been shown for tobacco (26). Additionally, the same pattern of hybridization occurs when either a 5 ' probe (containing only trnE) or a 3' probe (containing trnD and the

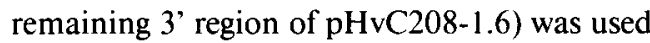
(data not shown). Therefore, to determine the 5' and 3' ends of the transcripts, S1 mapping was done. The results are summarized in Figure 7. The 531 base pair HindIII-Asp700 fragment was 5' end-labelled and digested with Rsal. The resulting 389 nucleotide fragment was used as the DNA template (Figure 7, probe 1). After hybridization with RNA, the S1 resistant fragments detected were approximately $147-8$ and 187 nucleotides in length. The end of the resistant hybrid of 147-8 nucleotides corresponded to the GT located 24-25 nucleotides upstream of the $\operatorname{trnE}$ gene and is the predicted initiation site (Figure 5A, c). In tobacco, the only other species where the chloroplast trnE RNA has been analyzed by $\mathrm{S} 1$ nuclease, the predicted initiation site is located at the $G$ in the identical sequence located 24 nucleotides upstream of the trnE gene (Figure 8).

When the 3' end-labelled 158 nucleotide HinfI-HaelII fragment (Figure 7, probe 2) spanning the trnE and $\operatorname{trn} Y$ genes was used for hybridization with RNA, the 158 bp hybrid fragment was protected confirming that the trnE and trnY genes are cotranscribed. For all experiments E. coli tRNA was also hybridized to the end-labelled DNA as a negative control resulting in lack of protection (data not shown).

Several DNA probes were used to determine whether trnD is cotranscribed with trnE and trnY. First a fragment which does not span the entire region from trnY to $\operatorname{trnD}$ was used. It consists of a 3' end-labelled 303 nucleotide fragment from the AluI site within trnY to the RsaI site 60 bases upstream from the trnD gene. The entire hybrid fragment was resistant to $S 1$ when it was assayed. Therefore, a fragment spanning from the Aval site in trnY to the HpaIl site 3' of the trnD gene was 3' end-labelled and assayed (Figure 7, probe 3). Two resistant hybrids, of 72 and 122 bp in length, were detected. The 72 bp resistant hybrid corresponds to the mature processed trnY. The end of the second resistant hybrid of 122 bp corresponds to the first $A$ in the sequence TTTTTCTCCCATAAAAT (Figure 5A, nucleotide 677). This end may signify a transcript intermediate containing both trnE and trnY. A third DNA template, which was 5' end-labelled, was also assayed. The fragment was $408 \mathrm{bp}$ and spanned from the AluI site within trnD into the trnY gene at the HaelII site (Figure 7, probe 4). A $46 \mathrm{bp}$ fragment was protected corresponding to the mature trn $\mathrm{D}$. In addition, a 408 bp resistant hybrid was detected after $\mathrm{S} 1$ digestion as expected for a transcript covering all three tRNA genes.

A 326 nucleotide 3' end-labelled AluI-HpaII fragment was used for analysis of the 3' end of the unprocessed transcript (Figure 7, probe 5). Three strong $S 1$ resistant hybrids were detected. One was 28 nucleotides in length, corresponding 
A

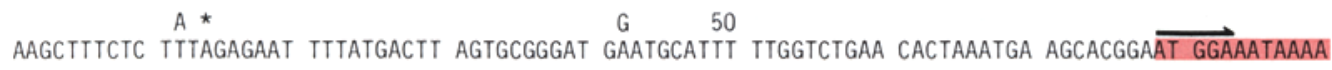
100 ACTCIIITIC ATCTIATCTI AGATCAATAA AATAACTACC TGTACTGAAC TAATCTAGAA TCCCTITTAG TAATCCATTC ITATTCTATA CATTIAAAT GAATTICCCT AAAAgGTAGA GGATGATCCA TGAATTAATC TAACCATCAA CTAAAAAAT CCTAGATGAA $\begin{array}{crrrr}\text { A } & \text { G } & 300 & T & \\ \end{array}$ AACATAGCAG AAAAGTTAGA AAAACTCTTT GCTITGGATC TAGTTATACT TTTCGAGTAT $\frac{\text { ATTGACAATT CAAAAAACT GCTCATACTA }}{\mathrm{i}} \frac{350}{\mathrm{~d}} \mathrm{e}$ TGATTATAGT ATAATCACGA GCGGTTGTAT ATGGCCCTAT CGTCTAGTGA TGCCCCTATC GTCTAGTGGT TCAGGACATCTCTCTITCAAG GAGGCAGCG GGGATTCGAC ITCCCCTGgG GGTAGgGagt ATTATGAAAG GAGGTTAATC ATAGATTAGC AAAAACCCTA GAATAAATTC

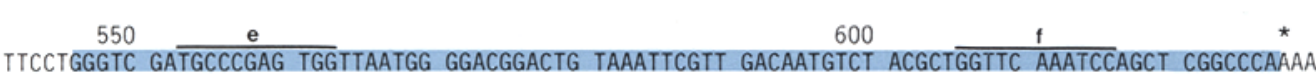

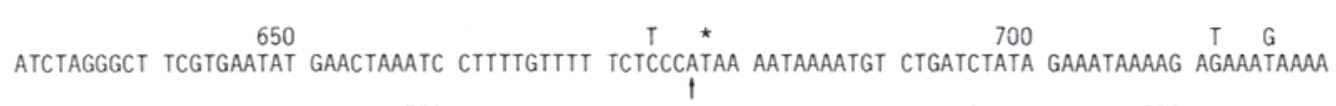

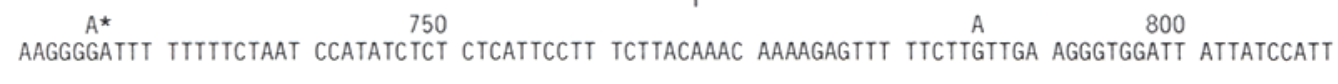
900

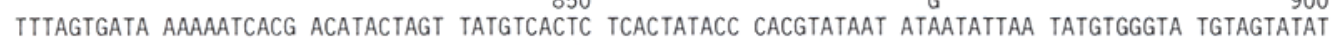

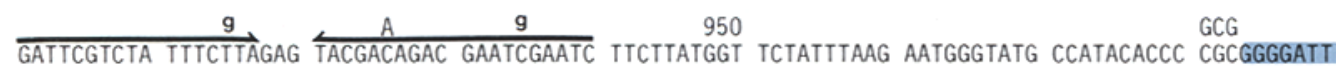

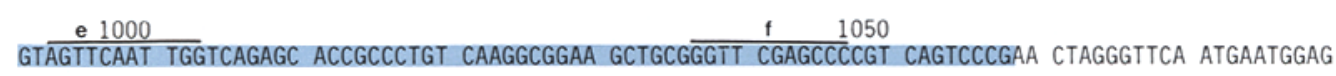

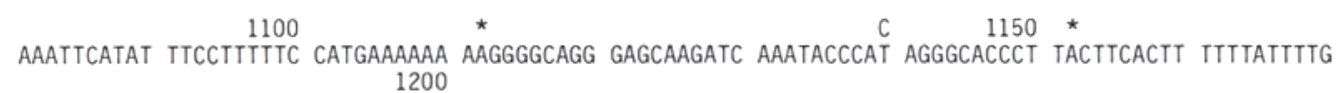

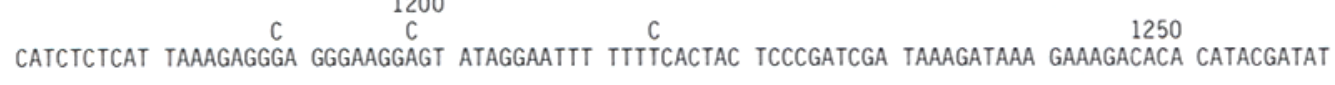
* $\quad$ * $1300 \quad * \quad * \quad$ *

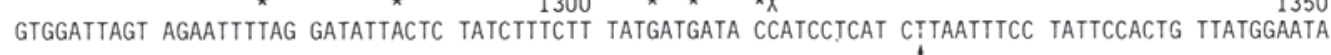
1400 GAGTACCGgt ATTTTACCGg AATCCATACA TAAATtGTAT TCCCTITTTA TTTCAGACCT CTITTCCCCA TCTCACTTCT ACTACTTATT 1450 1500

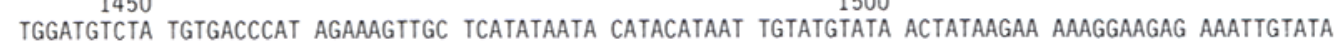

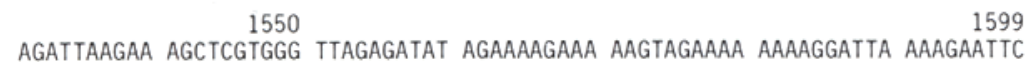

to the last nucleotide of the trnD gene. The other hybrid was approximately 291 nucleotides in length. The end of this fragment corresponds to the sequence CATCTTAATTTCC (Figure 5A, nucleotide 1322). This sequence does not resemble the sequence found to be the 3 ' end of the tobacco transcription unit (AAATCCTTATTTC) which was only 90 nucleotides downstream of the trnD gene (26). The last hybrid corresponded to the original size of the template indicating that one transcript extends even further, as expected from the Northern hybridization of Figure 6.

\section{DISCUSSION}

Identity of the $\delta$-ALA-RNA and glutamate tRNA: The $\delta$-ALA-RNA hybridizes to four bands in the chloroplast genome. Three of these bands must correspond to chloroplast HindIII 
$\operatorname{trnD}$ (GUC)

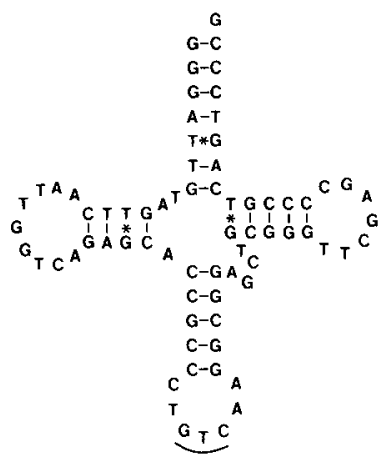

$\operatorname{trnY}(G \cup A)$

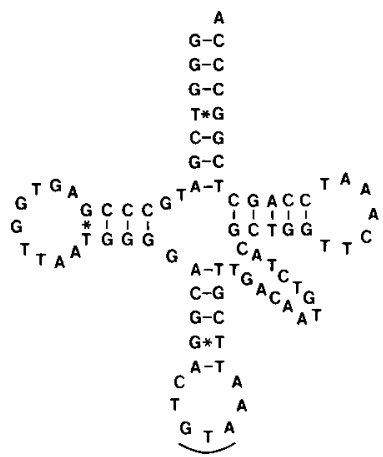

trnE (UUC)

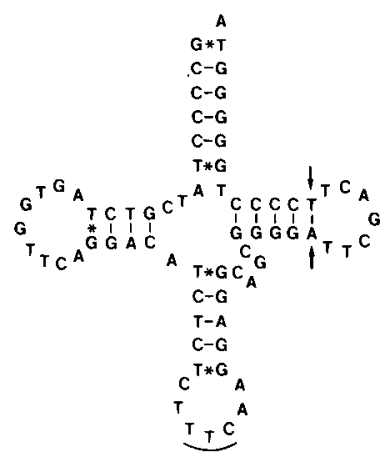

Figure 5. A. Complete nucleotide sequence of the barley chloroplast clone pHvC208-1.6. The blue color delineates the three tRNA genes. (Their order is tRNA ${ }^{\text {Glu }}$, tRNA ${ }^{\text {Tyr }}$, tRNA ${ }^{A s p}$ ). The 153 bp insertion in barley is marked in red. The wheat sequence is compared with the barley sequence: single nucleotide changes are written above the barley sequence and asterisks denote regions where small insertions or deletions have occurred. The $X$ marks the end of the published wheat sequence (30). Sequences designated with the letters a and i resemble -35 sequences, $b$ and $h$ resemble -10 sequences, $c$ and $d$ are transcription initiation sites, $e$ and $f$ denote internal eukaryotic polymerase III consensus sequences. Vertical arrows indicate probable 3 ' ends or processing sites of the transcript. The $\delta$-ALA-oligo '18-mer' sequence is shown. Horizontal arrows designate direct or inverted repeats. A large hairpin structure can be formed between the sequences marked with the letter $\mathrm{g}$. B. Cloverleaf structures for the three IRNA genes. The anticodons of the tRNAs are underlined. The A-T pair $(\uparrow)$ is unique to chloroplast $\operatorname{trn} E$ genes.

fragments which contain either tRNA genes with enough homology to $\delta$-ALA-RNA to cross hybridize under the conditions used or to tRNA genes hybridizing with tRNA species contaminating the $\delta$-ALA-RNA preparation. Hybridization of the four kbp band could be shown to be due to tRNA contaminating the $\delta$-ALA-RNA preparation: The $\delta$-ALA-RNA fraction gives rise to several stainable bands upon acrylamideurea gel electrophoresis. The RNAs from these bands can be eluted and assayed for their ability to function as tRNAs. Methionine and glycine tRNA activities were detected in bands isolated from the $\delta$-ALA-fraction (BERRY-LOWE and GouGH, unpublished data). Both methionine tRNA and glycine tRNA genes are encoded by pHvC35 (28). The sequence of glycine tRNA is more similar to glutamate tRNA than is methionine tRNA, so a synthetic oligomer to glycine tRNA was synthesized for use as a control hybridization probe. The results show

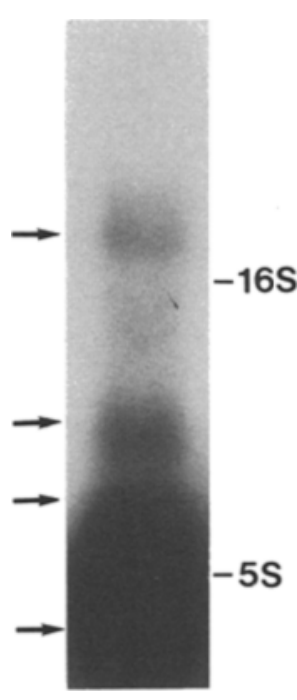

Figure 6. Autoradiogram of the "Northern" blot showing precursor and processed forms of the RNA. Chloroplast RNA isolated from plants grown in the light was denatured, electrophoresed through a $1 \%$ MOPS gel, and blotted onto nitrocellulose. The filter was hybridized in $50 \%$ formamide, $0.25 \%$ blotto (15), 5 X SSC, 50 mm-sodium phosphate buffer ( $\mathrm{pH} \mathrm{6.5)} \mathrm{at}$ $56^{\circ} \mathrm{C}$. The filter was washed at $56{ }^{\circ} \mathrm{C}$ in $2 \mathrm{X} \mathrm{SSC}$. Arrows on the left indicate the different hybridizing bands. E. coli rRNA size standards of $16 \mathrm{~S}$ rRNA (1541 nucleotides) and 5S rRNA (120 nucleotides) (Boehringer Mannheim) are shown on the right. 

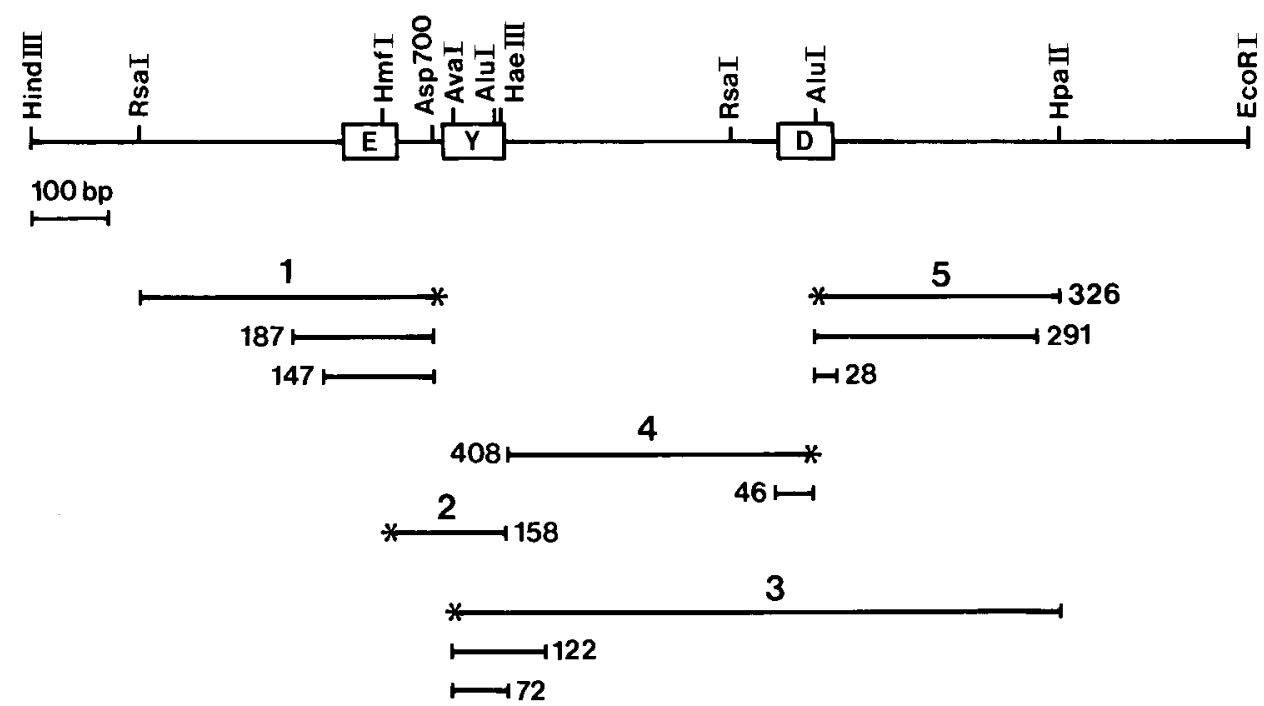

1 응

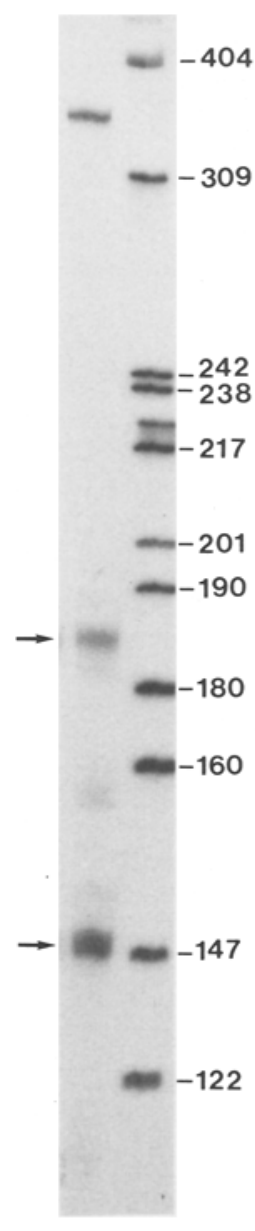

3 ํㅗ

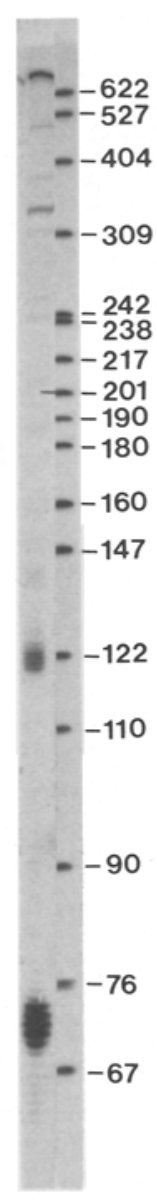

4 量

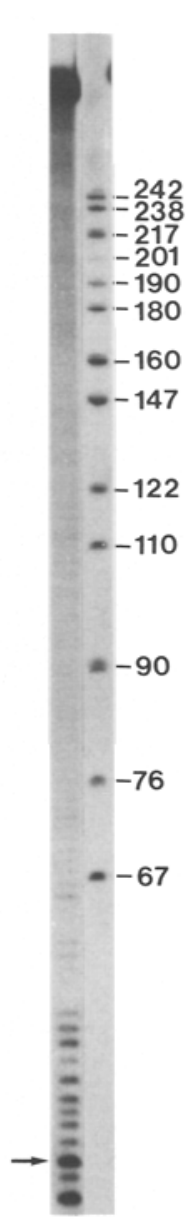

5 点

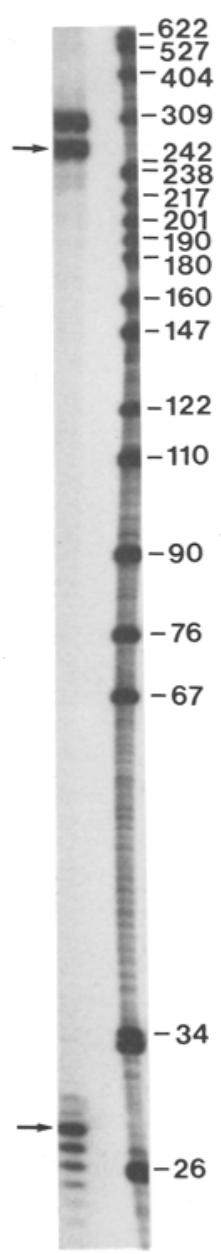


Figure 7. S1 nuclease analysis of the chloroplast clone pHvC208-1.6. The restriction site map of pHvC208-1.6 showing the location of the $\operatorname{trnE}, \operatorname{trn} Y$, and $\operatorname{trn} D$ genes is shown at the top of the figure. The probes used for $\mathrm{S} 1$ nuclease mapping (1-5) are shown below the diagram with asterisks indicating the ${ }^{32} \mathrm{P}-\mathrm{labelled}$ end and are discussed in the text. Below each probe are shown the respective SI nuclease resistant hybrids and their length in nucleotides. Autoradiograms of gels showing resistant hybrids after S1 nuclease treatment are shown below. Numbers above each track indicate the probe used. Arrows show the position of the resistant hybrids. The base pair standards (STD) consist of end-labelled pBR322 digested with Hpall (STD).

that strong hybridization occurred to the pHvC35 insert of four kbp when the GLY-oligo and $\delta$-ALA-RNA probes were used but not when $\delta$-ALA-oligo was the probe.

Sequence homology among species of this chloroplast region: The barley sequence is on average $94 \%$ homologous with the wheat sequence across the entire sequenced region. The three tRNA gene sequences are identical while the intergenic and flanking regions are highly homologous. This is not suprising since both barley and wheat are monocots. Extensive homology even in the intergenic regions was also reported between the dicots pea and broad bean (32). When monocot sequences are compared with dicot sequences homology is restricted to the region immediately 5' to the trnE gene and within the $\operatorname{trnE}$-trnY intergenic region. It has been proposed that during evolution several rearrangements have occurred in the chloroplast genome as monocots and dicots have diverged $(6,31)$. Although the three tRNA genes are within the region which has rearranged, they retain the same order and spacing. The homology in the 5' region of the trnE gene suggests that common regulatory elements are present.

The $1.6 \mathrm{kbp}$ HindIII-EcoRI sequence was examined for open reading frames. The largest open reading frame (ORF) upstream from the trnE gene is 33 amino acids in length. In the 3 '

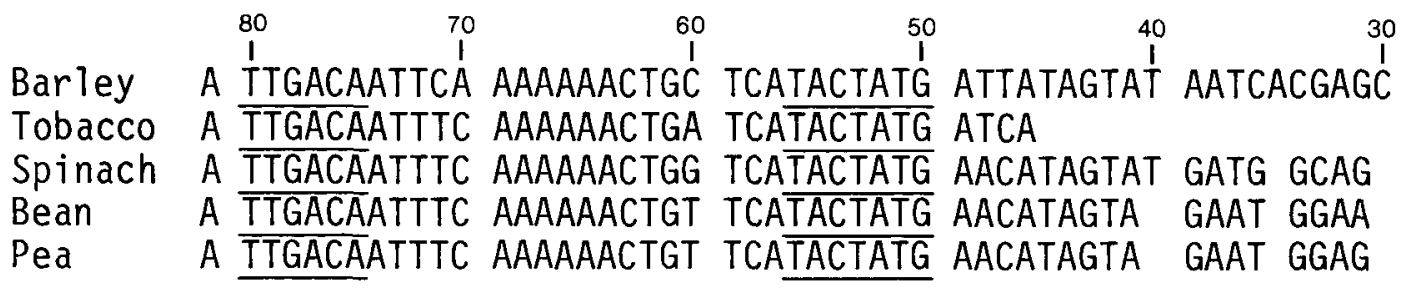

\begin{tabular}{|c|c|c|}
\hline Bar & GGTT GTAT A' GGC & TCTAGTGAT \\
\hline $\mathrm{CO}$ & TA GTATGAT GGCGGT TGG & TCAAGCAG \\
\hline & T GGGCACAT & AG GAT \\
\hline & AT CGGG CA & AG GAG \\
\hline & GT CGGG GA & AG GAT \\
\hline
\end{tabular}

Figure 8. Comparison of the barley, tobacco (26), spinach (14), broad bean (21), and pea (32) sequences immediately 5 ' to the glutamate tRNA gene. The underlined sequences are putative regulatory sequences and are discussed in the text. 
flanking region there are several open reading frames of 45 to 52 amino acids in length. No homology was found between any of these ORFs and the ORF154 of tobacco (36) or the ORF2136 or mbpX sequences of liverwort (27). An 82 codon ORF was found in the broad bean sequence just before the trnE gene (21). There is $50 \%$ amino acid homology with 19 codons of the 33 codon ORF in barley. The pea sequence also contains part of this ORF but it is shortened and has at least one deletion in it (32). Therefore, it is likely that this open reading frame is too small to encode a functional protein, particularly since no promoter-like sequences could be detected upstream of it.

Characterization of the RNA transcripts: The steady state levels of transcription of the three genes have been shown in barley (this paper), tobacco (26), spinach (14), and pea (32). POULSEN (29) detected three light-induced transcripts in the $\mathrm{pHvC2} 28$ region. However, two of these transcripts originate from within the pHvC35 clone and the other begins very far downstream from this region with the three tRNA genes. There was little or no effect of light on the steady state amount of these tRNA genes when the subcloned glutamate tRNA gene transcript of SP6 was used as a probe. When Northern blots were hybridized with this same probe four bands were detected. One corresponds to the processed size of the tRNA. Two other transcripts were about 450 and 230 nucleotides in length and these probably result from the partial processing of a precursor molecule. There was also one very large band of greater than two kb. This molecule is very large but must be the primary transcript which needs to be at least one $k b$ if the three tRNA genes are cotranscribed. The precursor for the cotranscription of the three tobacco genes is 400 nucleotides in agreement with the $\operatorname{trn} Y$-trnD intergenic region being only $108 \mathrm{bp}(26)$.

In barley there seem to be two strong initiation sites at the 5' end of the trnE gene. The first correlates to a GT sequence which is about 24 nucleotides upstream from the start of the gene (Figure 5A, c). This is identical to the start of transcription in tobacco (Figure 8) (26). The second site is about 63 nucleotides upstream from the trnE gene (Figure 5A, d, Figure 8).
There are sequences which are similar to -35 and -10 sequences (Figure 5A, i and h, respectively). There is good homology between all the higher plant sequences in the immediate 5' region, although the wheat and barley genes have an insertion in the region between the initiation site and the -10 sequence which is not present in the dicots (Figure 8).

S1 analysis identifies the three individual tRNAs, a transcript starting 5' to the trnE gene and ending approximately 930 bases downstream and 3' of the trnD gene. SI analysis also documents a transcript extending beyond the Hpall site of this region. Finally a transcript of about 450 bases covering only the trnE and trnY genes is identified.

Sequences involved in initiation of transcription: Chloroplast tRNA genes have both eukaryotic and prokaryotic promoter consensus sequences. The nucleotide sequences of chloroplast tRNA genes are more similar to those of prokaryotic tRNA genes. However the 3' CCA is not encoded by the chloroplast genome and chloroplast tRNAs may contain introns, two traits of eukaryotic tRNA genes. The regions of tRNA and protein genes likely to have regulatory sequences have been examined and compiled $(3,20,37)$. A prokaryotic-like -35 sequence has been proposed for plastids: ATTGANA (37), TTGACA (20), or TTGANT (3). This consensus sequence is separated by 14-25 nucleotides from a prokaryotic-like -10 sequence of: TAAGAT (37) or TATAAT $(3,20)$. However, in addition to these sequences, chloroplast tRNAs also have sequences homologous to two RNA polymerase III consensus sequences found within eukaryotic tRNA genes (35). These consensus sequences are: TGGCNNAGTGG and GGTTCGANNCC. Finally, the consensus sequence, GTANTAAAA, has been suggested for the 5' region of Euglena tRNA genes and has been detected in peas (32).

All of these sequences have been detected in the $1.6 \mathrm{kbp}$ fragment encoding the $\operatorname{trn} \mathrm{E}, \operatorname{trn} \mathrm{Y}$, and trnD genes (Figure 5A, a, b, c, d, e, f), although the Euglena consensus sequence is not found in the 5' region of trnE. These results are summarized in Figures $5 \mathrm{~A}$ and 8 . The specific function of each of these sequences is not fully known although deletions between the -35 and 
-10 sequences have resulted in decreased transcription (10) while chloroplast tRNAs containing the internal RNA polymerase III sequences (Figure 5A, e, f) were transcribed by HeLa cell transcription extracts (35). It is interesting to note that extracts from E. coli may transcribe from regions which resemble prokaryotic promoters but which in fact are not utilized by the homologous RNA polymerase in chloroplast extracts (10).

In conclusion, data are presented showing that the $\delta$-ALA-RNA gene is identical to the glutamate tRNA gene from barley chloroplasts. This glutamate IRNA gene is cotranscribed with the tyrosine tRNA gene and probably the aspartate $t R N A$ gene. They are transcribed in the dark and upon illumination. The DNA sequence of this region is almost identical to those from other chloroplasts. It has to be assummed that the $\delta$-ALA-RNA is distinguished from the glutamate $t R N A$ which functions in protein synthesis by posttranscriptional modifications.

\section{ACKNOWLEDGEMENTS}

1 would like to thank Prof. DITER VON Wettstein, Dr. Simon Gough, Dr. Richard Meagher, Dr. Verena Cameron-Mills and Dr. Gamini KanNangara for helpful discussions and reading the manuscript. I am indebted to $D r$. LIZ JACKSON for synthesis of the oligomers, Mrs. NinA RASMUSSEN for drawing the figures and Mrs. ANN-SOFI STEINHOLTz for the photography. B-L. was supported by an U.S. National Science Foundation Fellowship in Plant Biology.

\section{REFERENCES}

I. Bard, J.D.J., D.P.Bourque \& D. Zaitlin: Coupled transcription-translation in chloroplast lysates. In: Methods of Enzymology 118, A. Weissbach \& H. Weissbach, eds., Academic Press, New York, pp. 270-282 (1986)

2. BiRnboim, H. C. \& J. DolY: A rapid alkaline extraction procedure for screening recombinant plasmid DNA. Nucl. Acids Res. 7, 1513-1523 (1979)

3. BRiat. J. F., A. M. Lescure \& R. MaChE: Transcription of the chloroplast DNA: a review. Biochim. 68, $981-990$ (1986)

4. Chirgwin, J. M.. A. E. Przybyla, R. J. MacDonALD \& W. J. RUTTER: Isolation of biologically active ribonucleic acid from sources enriched in ribonu- clease. Biochem. 18, 5294-5299 (1979)

5. Clewell, D. B. \& D. K. Helinski: Supercoiled circular DNA protein complex in Escherichia coli: purification and induced conversion to an open circular DNA form. Proc. Nat. Acad. Sci. USA 62, 1159-1166 (1969)

6. Courtice, G. R. M., C. M. Bowman, T. A. Dyer \& J. C. GRAY: Localisation of genes for components of photosystem II in chloroplast DNA from pea and wheat. Curr. Genet. 10, 329-333 (1985)

7. Favaloro. J., R. Freisman \& R. Kamen: Transcription maps of polyoma vinus specific RNA: Analysis by two dimensional nuclease $\mathrm{S} 1$ gel mapping. In: Methods of Enzymology 65, L. Grossman \& K. Moldave, eds., Academic Press, New York, pp. 718-749 (1980)

8. Gruissem, W., B. M.Greenberg,G. Zurawski \& R. B. HALLICK: Chloroplast gene expression and promoter identification in chloroplast extracts. In: Methods of Enzymology 118, A. Weissbach \& H. Weissbach, eds., Academic Press, New York, pp. 253-270 (1986)

9. Grunstein, M.\&J. Wallis: Colony hybridization. In: Methods of Enzymology 68, R. Wu, ed., Academic Press, New York, pp. 379-389 (1979)

10. Hanley-Bowdoin, L. \& N. -H. Chua: Chloroplast promoters. Trends in Biochem. Science 12,67-70 (1987)

11. Herrmann, R. G.: The preparation of circular DNA from plastids. In: Methods in Chloroplast Molecular Biology, M. Edelman, R. B. Hallick, \& N. H. Chua, eds., Elsevier Biomedical Press, Amsterdam, pp. 259-279 (1982)

12. Hershfield, V.. H. W. Boyer, C. Yanofsky, M A. Lovetr \& D. R. Helinski: Plasmid ColEl as a molecular vehicle for cloning and amplification of DNA. Proc. Nat. Acad. Sci. USA 71, 3455-3459 (1974)

13. Hollingsworth, M. J. \& R. B. Hallick: Euglena gracilis chloroplast transfer RNA transcription units. J. Biol. Chem. 257, 12795-12799 (1984)

14. Holschuh, K., W. Bottomley \& P. R. Whitfield: Organization and nucleotide sequence of the genes for spinach chloroplast tRNA ${ }^{\text {Glu }}$ and tRNA ${ }^{\mathrm{Tyr}}$. Plant Molec. Biol. 3, 313-317 (1984)

15. Johnson, D. A.. J. W. Gautsch, J. R. Sportsman \& J. H. ELDER: Improved technique utilizing nonfat dry milk for analysis of proteins and nucleic acids transferred to nitrocellulose. Gene Anal. Techn. 1, 3-8 (1984)

16. Kannangara. C. G., S. P. Gough, B. Hansen, J. N. RASMUSSEN \& D. J. SiMPSON: A homogenizer with replaceable razor blades for bulk isolation of active barley plastids. Carlsberg Res. Commun. 42, 431439 (1977) 
17. Kannangara, C. G., S. P. Gough, R. P. Oliver \& S. K. RASMUSSEN: Biosynthesis of $\delta$-aminolevulinate in greening barley leaves. VI. Activation of glutamate by ligation to RNA. Carisberg Res. Commun. 49, 417-437 (1984)

18. KIRBY, K. S.: Isolation of nucleic acids with phenolic solvents. In: Methods of Enzymology 12B, L. Grossman \& K. Moldave, eds., Academic Press, New York, pp. 87.99 (1968)

19. KolodNer, R. \& K. K. Tewari: The molecular size and conformation of the chloroplast DNA from higher plants. Biochim. Biophys. Acta. 402, 372390 (1975)

20. KUNG, S. D. \& C. M. LiN: Chloroplast promoters from higher plants. Nucl. Acids Res. 13, 75437549 (1985)

21. Kuntz, M., J. H. Weil \& A. Steinmetz: Nucleotide sequence of a $2 \mathrm{kbp} \mathrm{BamHI}$ fragment of Vicia faba chloroplast DNA containing the genes for threonine, glutamic acid and tyrosine transfer RNAs. Nucl. Acids Res. 12, 5037-5047 (1984)

22. Maniatis, T., E. F. Fritsch \& J. Sambrook: In: Molecular cloning. Cold Spring Harbor Laboratory Press, New York (1982)

23. MAXAM, A. M. \& W. GiLberT: Sequencing end-labeled DNA with base-specific chemical cleavages. In: Methods of Enzymology 65, L. Grossman \& K. Moldave, eds., Academic Press, New York, pp. 499-560 (1980)

24. Melton, D. A., P. A. Krieg, M. R. Rebagliati, T. MANIATIS, K. ZINN\& M. R. GREEN: Efficient in vitro synthesis of biologically active RNA and RNA hybridization probes from plasmids containing a bacteriophage SP6 promoter. Nucl. Acids Res. 12, 7035-7056 (1984)

25. NaGao, R. T., D. M. Shah, V. K. ECKenRode \& R. B MEAGHER: Multigene family of actin-related sequences isolated from a soybean genomic library. DNA 1,1-9 (1981)

26. Ohme, M., T. Kamogashira \& M. Sugiura: Structure and cotranscription of tobacco chloroplast genes for $t R N A^{g l u}(U U C)$, $t R N A^{\text {tyr }}(G U A)$, and tRNA ${ }^{\text {asp }}$ (GUC). Nucl. Acids Res. 13, 1045-1056 (1985)

27. Ohyama, K., H. Fukuzawa, T. Kohchi, H. Shirai, T. Sano, S. Sano, K. Umesono, Y. Shiki. M. TAKEUCHI, Z. Chang, S. Aota, H. INOKUChI \& $\mathrm{H}$. OzEKI: Chloroplast gene organization deduced from complete sequence of liverwort Marchantia polymorpha chloroplast DNA. Nature 322,572 574 (1986)

28. OLIVER, R. P. \& C. POULSEN: Structure of a heavily transcribed region of barley chloroplast DNA. Transfer RNA genes from serine (UGA), glycine (GCC, UCC), formyl-methionine and threonine
(GGU). Carlsberg Res. Commun. 49, 647-673 (1984)

29. POULSEN, C.: The barley chloroplast genome: physical structure and transcriptional activity in vivo. Carlsberg Res. Commun. 48, 57-80 (1983)

30. Quigley, F., J. M. Grienenberger \& J. H. Weil: Localization and nucleotide sequences of the tRNA $A_{G C C}^{G \text { Gy }}, t R N A_{G \cup C}^{A s p}$ and $t R N A_{G C A}^{C y s}$ genes from wheat chloroplast. Plant Molec. Biol. 4, 305-310 (1985)

31. Quigley, F. \& J. H. Weil: Organization and sequence of five tRNA genes and of an unidentified reading frame in the wheat chloroplast genome: evidence for gene rearrangements during the evolution of chloroplast genomes. Curr. Gen. 9, 495503 (1985)

32. Rasmussen, O. F., B. M. Stummann \& K. W. HenNINGSEN: Nucleotide sequence of a $1.1 \mathrm{~kb}$ fragment of the pea chloroplast genome containing three tRNA genes, one of which is located within an open reading frame of 91 codons. Nucl. Acids Res. 12, 9143-9152 (1984)

33. SChon, A., G. Krupp, S. GoUgh, S. Berry-Lowe, C. G. KanNangara \& D. Söll: The RNA required in the first step of chlorophyll biosynthesis is a chloroplast glutamate IRNA. Nature 322, 281-284 (1986)

34. Shah, D. M.. R. C. Hightower \& R. B. Meagher: Complete nucleotide sequence of a soybean actin gene. Proc. Nat. Acad. Sci. USA. 79, 1022-1026 (1982)

35. Shapiro, D. R. \& K. K. Tewari: Nucleotide sequences of transfer RNA genes in the Pisum sativum chloroplast DNA. Plant Molec. Biol. 6, 1-12 (1986)

36. Shinozaki, K., M. Ohme, M. Tanaka, T. WakaSUgi, N. Hayashida, T. Matsubayashi, N. Zaita.J.

Chunwongse, J. Obokata, K. YamaguchiShinozaki, C. Ohto, K. Torazawa, B. Y. Meng, M. Sugita, H. Deno, T. Kamogashira, K. Yamada, J. Kusuda, F. Takaiwa, A. Kato, N. TohDoh, $\mathrm{H}$. Shimada \& M. Sugiura: The complete nucleotide sequence of the tobacco chloroplast genome: its gene organization and expression. EMBO J. 5, 2043-2049 (1986)

37. Steinmetz, A. A., E. T. Krebbers, Z. Schwarz, E. J. GUBBINS \& L. BOGORAD: Nucleotide sequences of five maize chloroplast transfer RNA genes and their flanking regions. J. Biol. Chem. 258, 55035511 (1983)

38. VIEIRA, J. \& J. MessinG: The pUC plasmids, an Ml3mp7-derived system for insertion mutagenesis and sequencing with synthetic universal primers. Gene 19, 259-268 (1982)

Accepted by H. KLENOW 